\title{
Effects of different luting cements and light curing units on the sealing ability and bond strength of fiber posts
}

\author{
Nilüfer Celebi BERIAT ${ }^{1}$, Ahmet Atila ERTAN² ${ }^{2}$, Zeliha YILMAZ $^{3}$, Gülsah GULAY² and Cem SAHIN ${ }^{1}$ \\ ${ }^{1}$ School of Dental Technology, Hacettepe University, Ankara, Turkey \\ ${ }^{2}$ Department of Prosthodontics, Faculty of Dentistry, Hacettepe University, Ankara, Turkey \\ ${ }^{3}$ Department of Endodontics, Faculty of Dentistry, Hacettepe University, Ankara, Turkey \\ Corresponding author, Zeliha YILMAZ; E-mail: dtzeliha@gmail.com, zeliha@hacettepe.edu.tr
}

\begin{abstract}
This study evaluated the sealing ability and push-out bond strength of two luting cements cured with two different types of light curing units (LCU): light-emitting diode (LED) versus quartz tungsten halogen (QTH). Forty teeth were divided into four groups (n=10/group). Quartz fiber posts (D.T. Light-Post) were luted to coronal or apical section of root canals using two types of resin cements (Panavia F or RelyX) cured with either LED LCU (Elipar FreeLight II) or QTH LCU (Optilux 501). Highest push-out bond strength was exhibited by QTH-cured RelyX, which was not significantly different from LED-cured RelyX but was higher than QTHcured Panavia F. The push-out bond strength of Panavia F did not differ with LCU type ( $p>0.05)$, but exhibited lower values than both QTH- and LED-cured RelyX. Fluid filtration test revealed that sealing ability was not influenced by luting cement type, but was significantly influenced by LCU type in favor of QTH light source: QTH-cured specimens displayed better seal than LED-cured ones $(p<0.05)$.
\end{abstract}

Keywords: Fiber post, Light curing units, Luting cement, Microleakage, Push-out bond strength

\section{INTRODUCTION}

Over the past decade, there is a perceived preference towards prefabricated glass and quartz fiber-reinforced resin posts over metal posts because of numerous superior advantages. Compared to metal posts, fiber posts have a lower modulus of elasticity which is similar to that of dentin and which results in reduced incidence of root fractures. Esthetically and functionally, fiber posts are viable non-metallic alternatives to meet higher esthetic demands ${ }^{1)}$ and to render better protection to endodontically treated teeth with a substantial degree of coronal destruction ${ }^{2,3)}$.

Despite these clear advantages, the use of fiber posts is also faced with several clear problems. Debonding is a common cause of failure associated with fiber posts ${ }^{2,4-6)}$. This type of failure typically results from unsuccessful adhesion to root canal dentin, which is characterized by less reliable adhesion compared to coronal dentin ${ }^{7,8)}$. Besides debonding, another common cause of fiber post failure is loss of retention due to delamination between the luting cement and the adhesive ${ }^{9)}$.

Several studies have investigated the bonding effectiveness of fiber-reinforced resin posts with regard to the effect of fiber post type, resin cement type, and application modalities ${ }^{7-9)}$. The effect of the type of curing light source was not investigated in these studies. It has been demonstrated that different types of light curing units (LCUs) affected the push-out bond strength of a dual-curable resin composite root canal sealer when used in conjunction with a polymer-based root canal

Color figures can be viewed in the online issue, which is available at J-STAGE.

Received Sep 30, 2011: Accepted Mar 27, 2012

doi:10.4012/dmj.2011-209 JOI JST.JSTAGE/dmj/2011-209 filling material ${ }^{10)}$.

With endodontic restorations, another leading cause of failure is salivary microleakage, which results in bacterial contamination of the root canal system by oral fluid/saliva ${ }^{11)}$. Despite the widespread use of fiber posts, information is scarce on the sealing ability of fiber post bonding. Among the various means available for measuring microleakage, the fluid filtration method seems to be a preferred method which provides nondestructive and quantitative volumetric data ${ }^{12)}$.

The purpose of this study was to evaluate the sealing ability and push-out bond strength of two different luting cements cured by two different types of light curing units when used to lute fiber posts at different locations (coronal versus apical) within the root canal. The hypotheses tested were that the type of luting cement and type of light curing unit would not affect the bonding effectiveness and sealing ability of fiber posts luted to root canal dentin.

\section{MATERIALS AND METHODS}

\section{Human tooth specimens}

Forty extracted, single-root, human teeth were selected for this study. Teeth with caries, cracks, or open apices were excluded. After the teeth were cleaned of adhering tissue remnants from their surfaces, they were rinsed and stored in distilled water until use.

1. Root canal instrumentation

The crowns were removed using a low-speed diamond disc under water cooling to a standardized root length of $16 \mathrm{~mm}$. Working length was established by subtracting 
$1 \mathrm{~mm}$ from this measured length. Pulpal remnants were removed using broaches. Apical patency was maintained throughout instrumentation by using a size 15 K-file (Antaeos, VDW, Munich, Germany). The canals were instrumented using a crown-down technique with ProTaper nickel-titanium rotary files (Dentsply Maillefer, Ballaigues, Switzerland) to F3. Each instrument was coated with RC Prep (Premier, PA, USA) as a lubricant. Between each increase in file size, the canals were irrigated with $2 \mathrm{~mL}$ of $2.5 \%$ sodium hypochlorite $(\mathrm{NaOCl})$. After instrumentation was completed, a final rinse was carried out using $5 \mathrm{~mL}$ of $2.5 \% \mathrm{NaOCl}$ and then the root canals were dried with sterile size 30 paper points.

\section{Root canal obturation}

A standardized, size 30 gutta-percha cone (Diadent, Seoul, Korea) was fitted into each root canal as a master cone and adjusted to working length with a tugback. The canal was then filled with AH-26 sealer and size 20 accessory gutta-percha cones using a lateral condensation technique. Accessory gutta-percha cones (Diadent, Seoul, Korea) were inserted until a size 25 finger spreader (Antaeos, VDW, Munich, Germany) could not penetrate past the coronal one-third of the root canal space. After obturation was completed, excess gutta-percha was removed using a hot plugger.

\section{Experimental groups}

Each root canal was prepared using the preparation drills from the kit of double-taper radiopaque translucent fiber post (D.T. Light-Post, Bisco, IL, USA). Four millimeters of gutta-percha was left intact in the apical region of the root canal, and \#2 $(1.8 \mathrm{~mm})$ tapered fiber post was cemented with a dual-cure resin cement. Four groups were formed ( $n=10$ /group) according to the types of resin cement and light curing unit used (Table 1).

\section{Group 1: Panavia F and LED LCU}

After irrigation and drying of the canals, equal amounts of ED Primer liquids A and B (Kuraray Co., Ltd., Okayama,
Japan) were mixed together on a mixing dish. Root canal walls were then treated with the self-etching ED primer for $60 \mathrm{~s}$ according to manufacturer's instructions. Excess primer was removed using paper points before drying the canals with a gentle air stream.

Equal amounts of Panavia F paste A and B (Kuraray Co., Ltd, Okayama, Japan) were mixed for $20 \mathrm{~s}$ and applied to the post space walls using a lentulo spiral instrument (Mani Inc., Tochigi, Japan). Fiber posts were covered with cement and slowly inserted into the root canal by finger pressure. Excess cement was carefully removed using a scalpel blade. Light curing of the cement was carried out using LED LCU (Elipar FreeLight II, 3M-ESPE, Seefeld, Germany) with a light intensity not less than $1,000 \mathrm{~mW} / \mathrm{cm}^{2}$ for $20 \mathrm{~s}$ at a standardized distance of $5 \mathrm{~mm}$ from the specimen surface. Oxyguard II gel (Kuraray, Osaka, Japan) was applied to the bonding margins of Panavia F cement and rinsed off after $3 \mathrm{~min}$.

\section{Group 2: Panavia F and QTH LCU}

Fiber posts were cemented with Panavia $\mathrm{F}$ and cured with QTH LCU (Optilux 501, Kerr, Orange, CA, USA) at a light intensity not less than $550 \mathrm{~mW} / \mathrm{cm}^{2}$ for $60 \mathrm{~s}$. All steps pertaining to the use of Panavia F cement to lute fiber posts to root canal dentin were carried out as per for Group 1 specimens.

\section{Group 3: RelyX and LED LCU}

After irrigation and drying of the canals, each root canal was etched for $15 \mathrm{~s}$, rinsed for $10 \mathrm{~s}$, and air-dried for 2 s. Excess moisture was removed using paper points. A single coat of Single Bond 2 adhesive (3M ESPE, Seefeld, Germany) was applied to the post space and allowed to air-dry for $5 \mathrm{~s}$. Adhesive light-curing was carried out after excess material was removed using paper points.

RelyX cement (3M ESPE, St Paul, MN, USA) was dispensed onto a mixing pad, mixed for $10 \mathrm{~s}$, and applied to the post space walls using a lentulo spiral instrument. To avoid any difficulty resulting from premature polymerization of the resin cement in the canal, the

Table 1 Experimental groups of this study according to the types of luting cement and light curing unit used

\begin{tabular}{|c|c|c|c|}
\hline Experimental group & Luting cement & Light curing unit & Fiber post \\
\hline Group 1 & $\begin{array}{l}\text { Panavia F (Kuraray Co., } \\
\text { Ltd., Okayama, Japan) }\end{array}$ & $\begin{array}{c}\text { LED (Elipar FreeLight } \\
\text { II, 3M-ESPE, Seefeld, } \\
\text { Germany) }\end{array}$ & $\begin{array}{l}\text { D.T. Light-Post } \\
\text { (Bisco, IL, USA) }\end{array}$ \\
\hline Group 2 & $\begin{array}{l}\text { Panavia F (Kuraray Co., } \\
\text { Ltd., Okayama, Japan) }\end{array}$ & $\begin{array}{l}\text { QTH (Optilux 501, Kerr, } \\
\text { Orange, CA) }\end{array}$ & $\begin{array}{l}\text { D.T. Light-Post } \\
\text { (Bisco, IL, USA) }\end{array}$ \\
\hline Group 3 & $\begin{array}{c}\text { RelyX (3M ESPE, St Paul, } \\
\text { MN, USA) }\end{array}$ & $\begin{array}{c}\text { LED (Elipar FreeLight } \\
\text { II, 3M-ESPE, Seefeld, } \\
\text { Germany) }\end{array}$ & $\begin{array}{l}\text { D.T. Light-Post } \\
\text { (Bisco, IL, USA) }\end{array}$ \\
\hline Group 4 & $\begin{array}{c}\text { RelyX (3M ESPE, St Paul, } \\
\text { MN, USA) }\end{array}$ & $\begin{array}{c}\text { QTH (Optilux 501, Kerr, } \\
\text { Orange, CA) }\end{array}$ & $\begin{array}{l}\text { D.T. Light-Post } \\
\text { (Bisco, IL, USA) }\end{array}$ \\
\hline
\end{tabular}


fiber post which was coated with a thin layer of cement was inserted immediately after cement placement. Any excess cement was removed, and the post was maintained under constant finger pressure. Light-curing of the cement was carried out using LED LCU.

\section{Group 4: RelyX and QTH LCU}

Fiber posts were cemented with RelyX but light-cured using QTH LCU. All steps pertaining to the use of RelyX cement to lute fiber posts to root canal dentin were carried out as per for Group 3 specimens.

\section{Fluid filtration test}

A modified fluid filtration test was used to quantitatively measure apical leakage ${ }^{13)}$ (Fig. 1) by following the movement of a tiny air bubble traveling within a 0.1 $\mathrm{mL}$ micropipette of uniform bore. All pipettes, syringes, and plastic tubes used in the fluid filtration model of this study were filled with deionized water.

A micropipette was connected to a plastic tube, which in turn was attached to a tooth root specimen with epoxy resin (Pattex, Henkel, Düsseldorf, Germany). Using a microsyringe, water was drawn back by approximately $2 \mathrm{~mm}$ to introduce a tiny air bubble in the micropipette and the air bubble was subsequently adjusted to a designated position within the micropipette. Using a compressed air tank, air pressure regulated at 121.6 $\mathrm{KPa}\left(1,240 \mathrm{~cm} \mathrm{H}_{2} \mathrm{O}\right)^{14)}$ was applied at the apical end of the root specimen, forcing water through any voids along the root canal filling. Water movement displacing the air bubble in the capillary tube was measured per unit of time. Linear displacement of this air bubble was converted to volume displacement and recorded as the fluid transported in $\mathrm{mL} / \mathrm{h}$.

For specimens serving as positive control, teeth selection criteria and root canal instrumentation procedure were likewise applied as described for the four experimental groups, except that the prepared root canal space was not obturated. Fluid flow rate through the unfilled root canal was measured by recording the air bubble movement through the root canal in $1 \mathrm{~h}(1,428$ $\mathrm{mL} / \mathrm{min} / \mathrm{cm} \mathrm{H}_{2} \mathrm{O}$ ). This value served both as a positive control and as $100 \%$ leakage, against which the leakage values of the obturated root canals would be compared.

Push-out bond strength test

Using a low-speed saw (Isomet 4000, Buehler, IL, USA) under water cooling, roots were sectioned perpendicular to their long axis into 1-mm-thick slices. For each experimental group, two slices were obtained from each root (Fig. 2): one slice from the apical region $(6 \mathrm{~mm}$ above apex) and the other from the coronal region (12 mm above apex).

After measuring and confirming the thickness of each slice with a digital caliper, the fiber post adhesively bonded to root dentin slice was loaded with a $0.5-\mathrm{mm}$ diameter stainless steel cylindrical plunger. The plunger tip was sized and positioned such that it was in contact with the fiber post only (Fig. 2). Due to the convergence of root canal walls, push-out force was applied from the apical side to the coronal side. Loading was performed in a universal testing machine at a crosshead speed of $0.5 \mathrm{~mm} / \mathrm{min}$ until bond failure occurred. Applied force was recorded using Nexygen Data Analysis Software (Ametek, Largo, USA), and the debonding values were used to calculate push-out strengths in megapascals (MPa) according to the formula below ${ }^{15)}$ :

$$
\text { Push-out bond strength }(\mathrm{MPa})=\frac{\text { Maximum load }(\mathrm{N})}{\text { Adhesion area of fiber post }\left(\mathrm{mm}^{2}\right)}
$$

Bonded area of each root dentin slice was calculated using the formula below:

$$
\text { Bonded area of dentin slice }=\pi\left(\mathrm{r}_{1}+\mathrm{r}_{2}\right) \times \mathrm{S}
$$

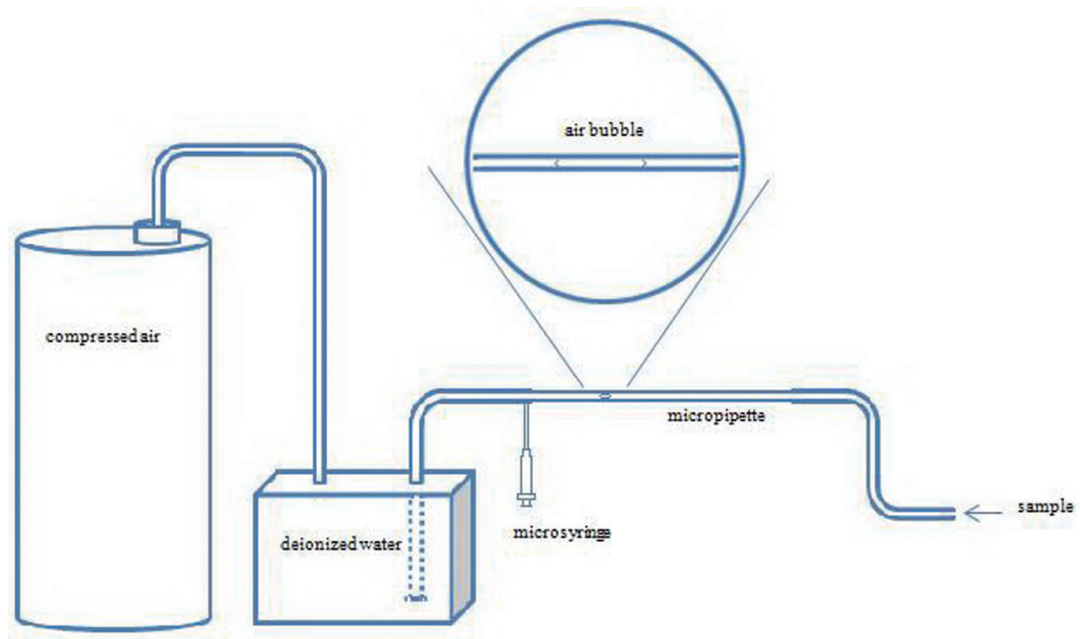

Fig. 1 Schematic diagram of fluid filtration model used in this study. 

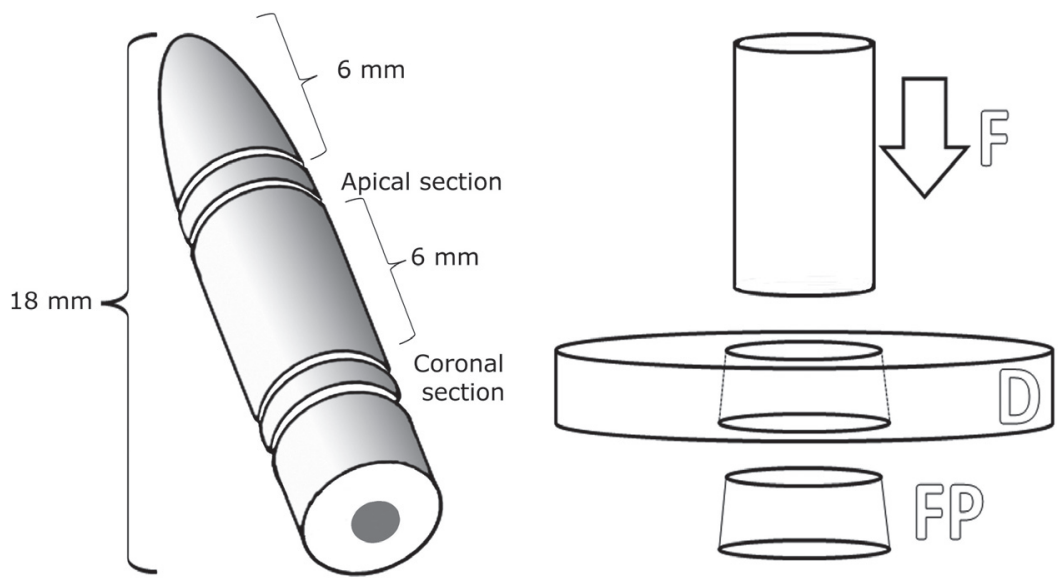

Fig. 2 Schematic illustration of apical and coronal root dentin slices used for push-out test and test setup, where F: direction of force; D: root dentin slice; and FP: fiber post.
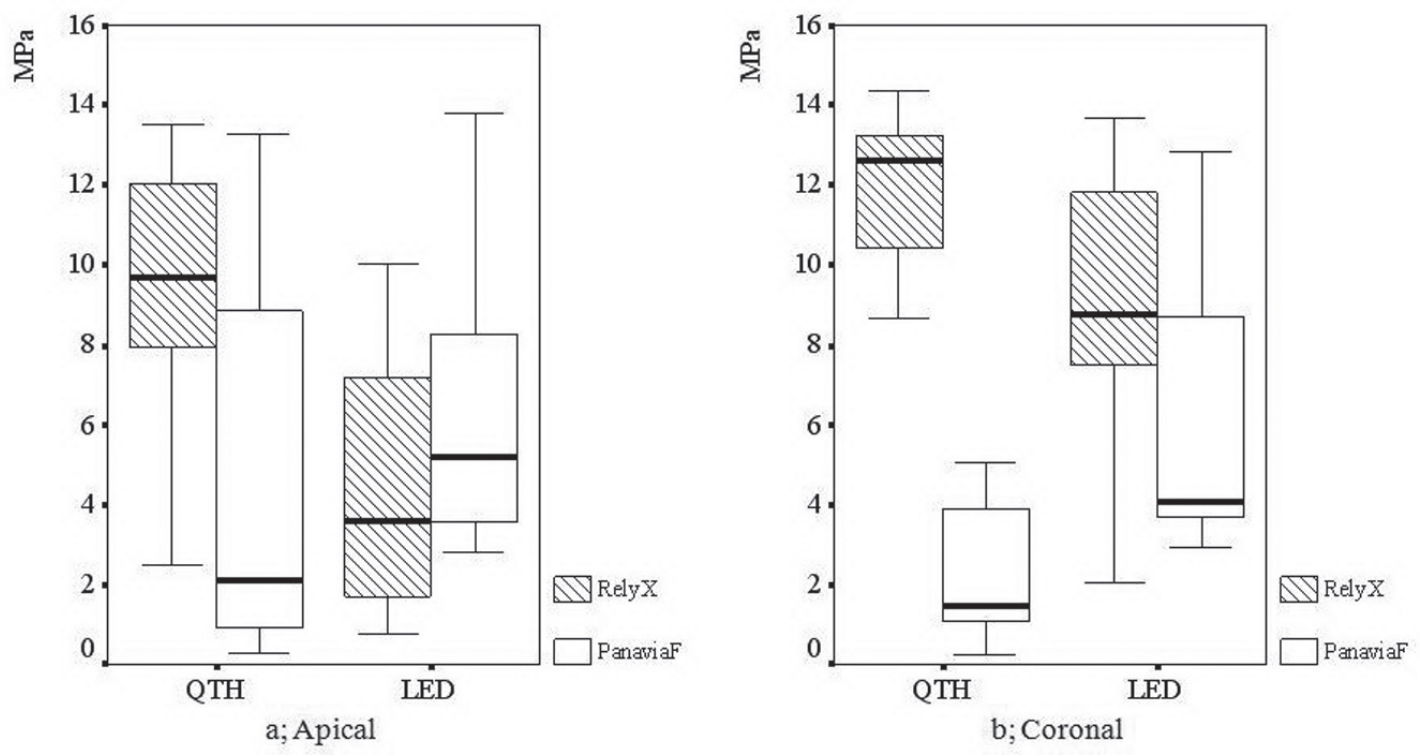

Fig. 3 Box plot of push-out bond strengths at: (a) apical third; and (b) coronal third.

S was calculated as follows:

$$
\mathrm{S}=\sqrt{\left(\mathrm{r}_{1}-\mathrm{r}_{2}\right)^{2}+\mathrm{h}^{2}}
$$

where $r_{2}$ is the coronal radius, $r_{1}$ is the apical radius, and $\mathrm{h}$ is the thickness of the slice.

Statistical analysis was performed using nonparametric Mann-Whitney U test at 0.05 significance level among the test groups.
Failure mode analysis

After push-out bond strength testing, all dentin slices were visually inspected under a stereomicroscope to determine their failure modes. Representative slices selected from each experimental group were analyzed using a scanning electron microscope (SEM).

\section{RESULTS}

Push-out bond strength

Figures 3(a) and 3(b) show the minimum, maximum, and median push-out bond strength values at the apical and 
coronal sections respectively. Results showed that pushout bond strength of fiber posts was not significantly affected by luting cement type $(p>0.001)$. On the influence of location within the root canal, only Group 3 (RelyX-LED) demonstrated a significant difference between the different regions of the root $(p=0.013)$.
At the coronal section (Fig. 3b), there were significant differences among luting cement-LCU combinations $(p<0.001)$. Highest bond strength was exhibited by Group 4 (RelyX-QTH) (12.61 $\pm 3.3 \mathrm{MPa})$, which was not significantly different from that of Group 3 (RelyX-LED) $(8.77 \pm 3.2 \mathrm{MPa})$ but was significantly higher $(p<0.05)$

Table 2 Distribution of failure modes of specimens

\begin{tabular}{cccccc}
\hline $\begin{array}{c}\text { Cement-LCU } \\
\text { combination }\end{array}$ & Root section & $n$ & Adhesive & Cohesive & Mixed \\
\hline \multirow{2}{*}{ Panavia F-QTH } & Apical & 10 & 8 & 1 & 1 \\
& Coronal & 10 & 9 & 1 & 0 \\
\multirow{2}{*}{ RelyX-QTH } & Apical & 10 & 7 & 2 & 1 \\
\multirow{2}{*}{ Panavia F-LED } & Coronal & 10 & 9 & 0 & 1 \\
\multirow{2}{*}{ RelyX-LED } & Apical & 10 & 9 & 1 & 0 \\
& Coronal & 10 & 7 & 1 & 2 \\
\hline
\end{tabular}

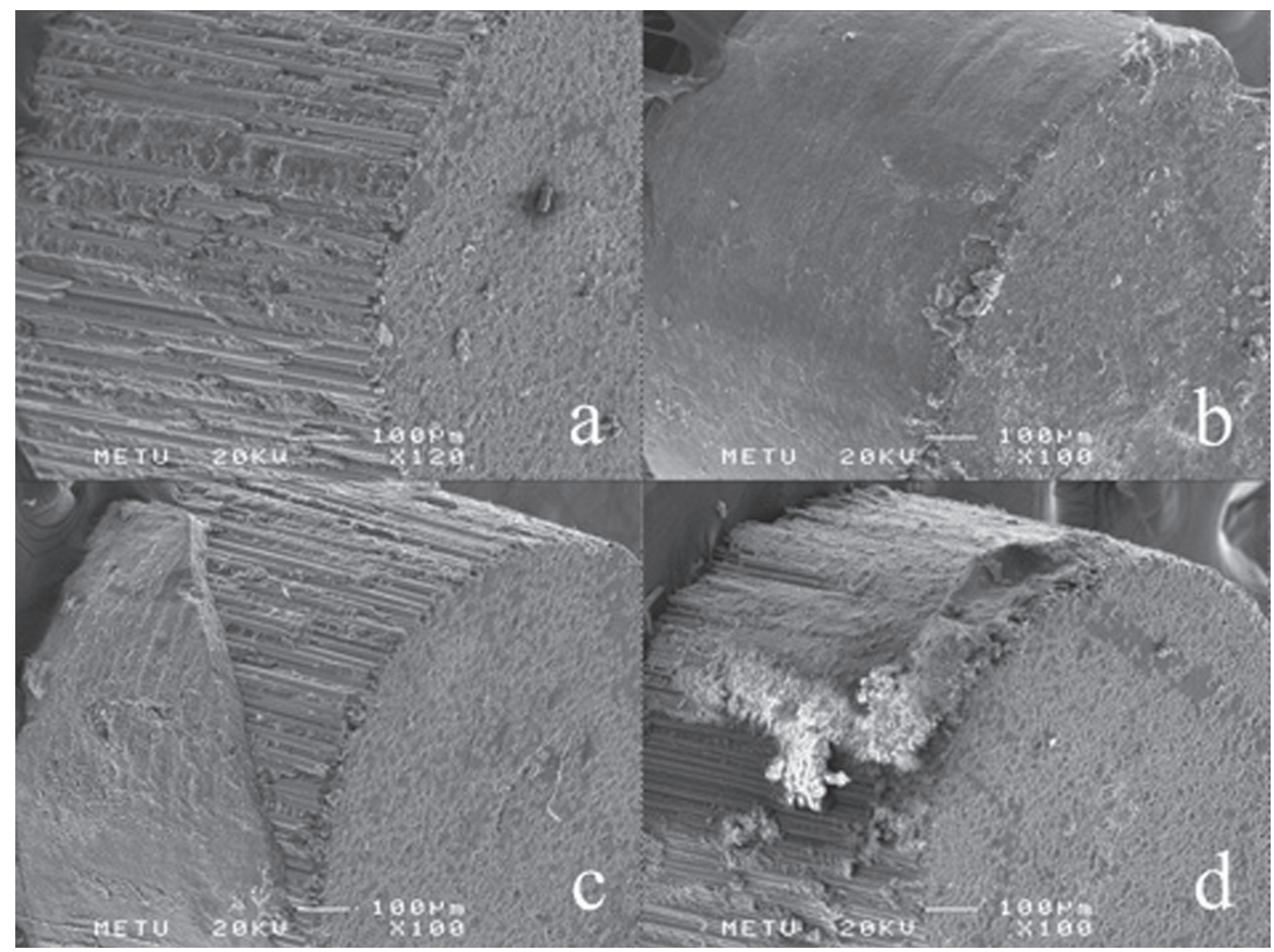

Fig. 4 SEM images of representative failed specimens from each experimental group. (a) Panavia F-QTH: adhesive failure. (b) RelyX-QTH: cohesive failure. (c) RelyX-LED: cohesive failure. (d) Panavia F-LED: cohesive failure. 


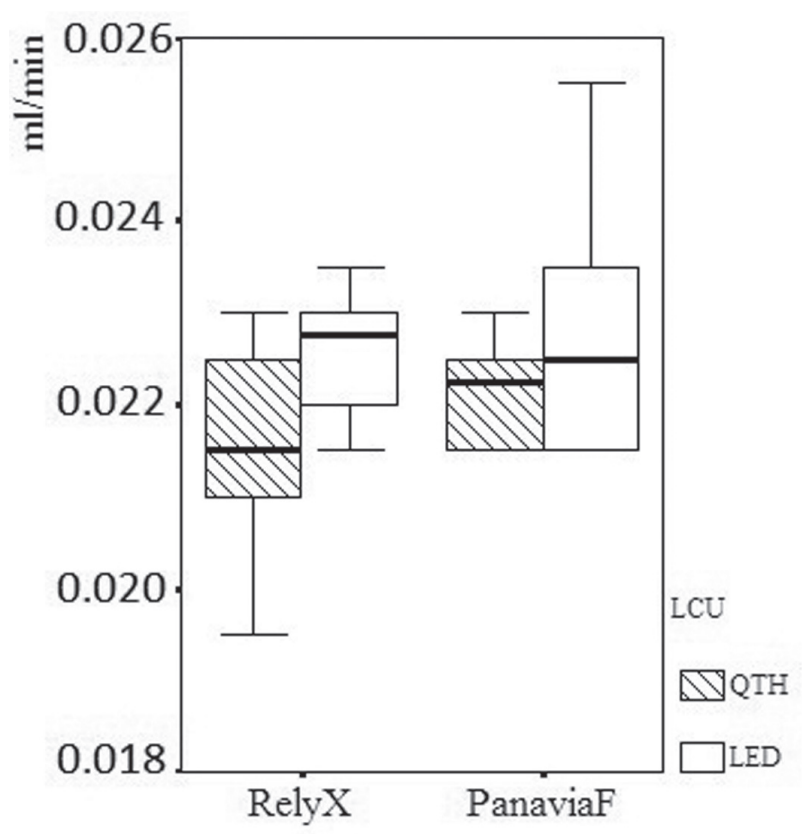

Fig. 5 Box plot of fluid conductance values.

than that of Group 2 (Panavia F-QTH) (1.44 $\pm 3.2 \mathrm{MPa})$. For Panavia F specimens, bond strength of Group 1 (Panavia F-LED) (4.1 $\pm 3.6 \mathrm{MPa})$ was not significantly different ( $p>0.05$ ) from that of Group 2 (Panavia F-QTH) $(1.44 \pm 3.2 \mathrm{MPa})$ but was significantly lower than RelyX specimens in Groups 3 and 4.

At the apical section, Group 4 (RelyX-QTH) showed the highest bond strength while Group 2 (Panavia F-QTH) the lowest (Fig. 3a). Nonetheless, there were no significant differences among the luting cement-LCU combinations $(p=0.103)$.

\section{Failure modes}

Table 2 shows the distribution of failure modes for each luting cement-LCU combination and at apical and coronal sections respectively. Figure 4 shows the SEM images of the representative failed specimens from each experimental group.

\section{Sealing ability}

Figure 5 shows the fluid conductance values according to luting cement-LCU combination. Sealing ability was found to be significantly affected by LCU type ( $p=0.003)$, as indicated by these median values and standard errors: RelyX-QTH (0.0214 $\pm 0.001 \mathrm{~mL} / \mathrm{min})$, RelyX-LED (0.0226 $\pm 0.0007 \mathrm{~mL} / \mathrm{min})$, Panavia F-QTH $(0.0224 \pm 0.001$ $\mathrm{mL} / \mathrm{min})$, Panavia F-LED (0.0229 $\pm 0.001 \mathrm{~mL} / \mathrm{min})$.

\section{DISCUSSION}

In the present study, the sealing ability and push-out bond strength of fiber posts were evaluated using two types of luting cements and two types of LCUs. The hypothesis that luting cement type would not affect sealing ability was accepted. However, the hypothesis that LCU type would not affect sealing ability was rejected. On bonding effectiveness, the hypothesis that luting cement type and LCU type would not affect bonding effectiveness was accepted.

\section{Bond strength of fiber posts}

Among the different mechanical tests available to evaluate bond strength, push-out bond strength test is considered to be a viable alternative means to assess fiber post adhesion to root canal dentin ${ }^{16)}$. When compared with microtensile test, push-out test has been shown to be more dependable in measuring the bond strength of luted fiber posts: no occurrence of premature failures and acceptable variability in data distribution ${ }^{17,18)}$. Other advantages of push-out test for fiber post bonding include: easy to perform, easy specimen preparation, availability of multiple specimens out of one root, and thus regional differences in bond strength among root dentin levels could be assessed ${ }^{17,18)}$. On the other hand, this method also has its own shortcomings such as difference in dislodging forces in-vitro and in-vivo and introduction of preparation artifacts while sectioning.

On the influence of luting cement type, RelyX demonstrated higher push-out bond strengths than Panavia F in the current study, especially at the coronal section. This result agreed with a previous study by Bitter et al. ${ }^{7}$. However, this same study ${ }^{7)}$ also reported that the apical region of root canal had significantly higher bond strengths than the middle and coronal regions, contradicting the findings of this study. On the influence of root canal dentin region, there were significant differences in push-out bond strength between the root sections for RelyX cement, with the coronal section demonstrating higher bond strengths. For Panavia F, there were no significant differences between the root sections.

On the influence of LCU type, the present data showed that the LCUs tested might have a probable effect on the push-out bond strength of the adhesive cements used for fiber post luting. QTH light generated a relatively wide spectral emission profile with a moderate power density level, whereas LED units generated a high power density over a narrow spectral range. Studies have shown that the type of curing light and curing mode impacted the polymerization kinetics of resin-based materials ${ }^{19,20)}$. These studies demonstrated that polymerization kinetics was dependent on power density and spectral output of light curing sources. In this study, the higher bond strengths obtained with QTH could be attributed to a slower monomer conversion polymerization process. QTH LCU cured the resin-based composite materials slower than the LED LCU, allowing the bonding material to flow in the pre-gel stage ${ }^{19)}$. This then provided some stress relief from polymerization shrinkage/contraction at the resin-dentin interface and improved the bond strength ${ }^{19,21)}$.

\section{Sealing ability of fiber post bonding}

In endodontic applications, microleakage is a weightier 
concern than bond strength. Even if a material has relatively low bond strength to dentin, it may be a good obturating material if it is effective in preventing microleakage ${ }^{22)}$.

The fluid transport model, developed by Pashley et $a l .{ }^{23)}$, has been widely used to determine leakage around coronal restorations and endodontic retrograde fillings ${ }^{24}$. This model has since been modified to quantitatively measure leakage around fiber posts ${ }^{25}$, and this method has been shown to be more sensitive than bacterial penetration and conventional dye penetration methods for the detection of full length voids along root canals and to be highly reproducible ${ }^{26)}$. Additionally and favorably, specimens used in fluid filtration test can be subsequently used for push-out bond strength test because of its non-destructive nature. In this study, the fluid flow rate of unfilled root canal was used as a positive control to confirm the effectiveness of this test method in detecting leakage and hence to minimize the generation of false negative results.

In this study, none of the investigated luting materials achieved a homogeneous and tight seal at the post-cement-dentin interface, as leakage was present with both luting cements. Results showed that sealing ability was not influenced by luting cement type, but was significantly affected by LCU type $(p=0.003)$ in favor of the QTH unit. For both RelyX and Panavia F cements, QTH-cured specimens exhibited a better seal, which could be attributed to the wider spectral emission of QTH.

Results of this study showed a good correlation between push-out bond strength and sealing ability. RelyX specimens exhibited the highest bond strength values accompanied by the lowest microleakage values. Resin penetration into dentinal tubules played a critical role in both the bond strength and sealing ability of fiber post bonding. On this premise, RelyX might have penetrated deeper into the dentinal tubules than Panavia $\mathrm{F}$ to provide better sealing and bonding effectiveness. Conversely, Panavia $\mathrm{F}$ appeared to be inadequate at both sealing and bonding.

\section{Effect of root dentin location on bond strength of fiber posts}

In the present study, bond strengths at the coronal section were higher than those of the apical section. However standard deviation values spanned over a wide range. This could be attributed to dentin structural variations of specimens with root dentin location. Tubular and microstructural inhomogeneities are present even within the same tooth, which then result in varied bond strengths even with the same luting agent.

It should also be highlighted that the transmission of curing light decreased from the coronal section to the apical section. Therefore, it was highly likely that incomplete polymerization of luting cements at the apical section of root canal diminished the bond strength of fiber posts luted to apical dentin.

\section{CONCLUSIONS}

Within the limitations of this study, the following conclusions were drawn:

1. Leakage was present in every luting cementLCU combination, indicating that none of the investigated luting materials achieved a homogeneous and tight seal at the post-cementdentin interface. Nonetheless, QTH-cured specimens showed better sealing performance than LED-cured ones.

2. On bonding effectiveness, there were no significant differences in bond strength among all the luting cement-LCU combinations at the apical section of root canal.

3. For both sealing ability and bonding effectiveness, RelyX-QTH combination exhibited the best overall performance.

\section{REFERENCES}

1) Vichi A, Ferrari M, Davidson CL. Influence of ceramic and cement thickness on the masking of various types of opaque posts. J Prosthet Dent 2000; 83: 412-417.

2) Ferrari M, Vichi A, Garcia-Godoy F. Clinical evaluation of fiber-reinforced epoxy resin posts and cast post and cores. Am J Dent 2000; 13: 15B-18B.

3) Mannocci F, Bertelli E, Sherriff M, Watson TF, Ford TR. Three-year clinical comparison of survival of endodontically treated teeth restored with either full cast coverage or with direct composite restoration. J Prosthet Dent 2002; 88: 297301.

4) Ferrari M, Cagidiaco MC, Goracci C, Vichi A, Mason PN, Radovic I, Tay F. Long-term retrospective study of the clinical performance of fiber posts. Am J Dent 2007; 20: 287-291.

5) Fredriksson M, Astback J, Pamenius M, Arvidson K. A retrospective study of 236 patients with teeth restored by carbon fiber-reinforced epoxy resin post. J Prosthet Dent 1998; 80: 151-157.

6) Naumann M, Blankenstein F, Kiessling S, Dietrich T. Risk factors for failure of glass fiber-reinforced composite post restorations: a prospective observational clinical study. Eur J Oral Sci 2005; 113: 519-524.

7) Bitter K, Meyer-Lueckel H, Priehn K, Kanjuparambil JP, Neumann K, Kielbassa AM. Effects of luting agent and thermocycling on bond strengths to root canal dentine. Int Endod J 2006; 39: 809-818.

8) Ferrari M, Goracci C, Sadek FT, Monticelli F, Tay FR. An investigation of the interfacial strengths of methacrylate resin-based glass fiber post-core buildups. J Adhes Dent 2006; 8: 239-245.

9) Mannocci F, Bertelli E, Watson TF, Ford TP. Resin-dentin interfaces of endodontically-treated restored teeth. Am J Dent 2003; 16: 28-32.

10) Nagas E, Cehreli ZC, Durmaz V, Vallittu PK, Lassila LV. Regional push-out bond strength and coronal microleakage of Resilon after different light-curing methods. J Endod 2007; 33: 1464-1468.

11) $\mathrm{Wu}$ MK, Pehlivan $\mathrm{Y}$, Kontakiotis EG, Wesselink PR. Microleakage along apical root fillings and cemented posts. J Prosthet Dent 1998; 79: 264-269.

12) Derkson GD, Pashley DH, Derkson ME. Microleakage measurement of selected restorative materials: a new in vitro method. J Prosthet Dent 1986; 56: 435-440.

13) Fogel HM. Microleakage of posts used to restore endodontically treated teeth. J Endod 1995; 21: 376-379. 
14) Usumez A, Cobankara FK, Ozturk N, Eskitascioglu G, Belli $\mathrm{S}$. Microleakage of endodontically treated teeth with different dowel systems. J Prosthet Dent 2004; 92: 163-169.

15) Patierno JM, Rueggeberg FA, Anderson RW, Weller RN, Pashley DH. Push-out strength and SEM evaluation of resin composite bonded to internal cervical dentin. Endod Dent Traumatol 1996; 12: 227-236.

16) Goracci C, Grandini S, Bossu M, Bertelli E, Ferrari M. Laboratory assessment of the retentive potential of adhesive posts: a review. J Dent 2007; 35: 827-835.

17) Goracci C, Tavares AU, Fabianelli A, Monticelli F, Raffaelli O, Cardoso PC, Tay F, Ferrari M. The adhesion between fiber posts and root canal walls: comparison between microtensile and push-out bond strength measurements. Eur J Oral Sci 2004; 112: 353-361.

18) Cekic-Nagas I, Ergun G, Nagas E, Tezvergil A, Vallittu PK, Lassila LV. Comparison between regional micropush-out and microtensile bond strength of resin composite to dentin. Acta Odontol Scand 2008; 66: 73-81.

19) Neves AD, Discacciati JA, Orefice RL, Yoshida MI. Influence of the power density on the kinetics of photopolymerization and properties of dental composites. J Biomed Mater Res B
Appl Biomater 2005; 72: 393-400.

20) Watts DC. Reaction kinetics and mechanics in photopolymerised networks. Dent Mater 2005; 21: 27-35.

21) Braga RR, Ferracane JL, Condon JR. Polymerization contraction stress in dual-cure cements and its effect on interfacial integrity of bonded inlays. J Dent 2002; 30: 333340.

22) Schwartz RS. Adhesive dentistry and endodontics. Part 2: bonding in the root canal system - the promise and the problems: a review. J Endod 2006; 32: 1125-1134.

23) Pashley DH, Andringa HJ, Derkson GD, Derkson ME, Kalathoor SR. Regional variability in the permeability of human dentine. Arch Oral Biol 1987; 32: 519-523.

24) Wu MK, De Gee AJ, Wesselink PR, Moorer WR. Fluid transport and bacterial penetration along root canal fillings. Int Endod J 1993; 26: 203-208.

25) Rutledge RE, Montgomery S. Effect of intracanal medicaments on the sealing ability of TERM. J Endod 1990; 16: 260-264.

26) Goldman M, Simmonds S, Rush R. The usefulness of dyepenetration studies reexamined. Oral Surg Oral Med Oral Pathol 1989; 67: 327-332. 